\title{
Tumour necrosis factor in synovial exudates
}

\author{
FRANCESCOS DI GIOVINE, GEORGE NUKI, AND GORDON W DUFF \\ From the University of Edinburgh Department of Medicine, Rheumatic Diseases Unit, Northern Genera \\ Hospital, Edinburgh, UK
}

SUMMARY The actions of tumour necrosis factor (TNF) include resorption of bone and cartilage $\overrightarrow{\vec{Z}}$ suggesting a potential role in the pathogenesis of arthritis. TNF activity was looked for in synovia他 fluids from 137 patients with different rheumatic diseases. Unfractionated samples were tested iñ the L929 bioassay. Significant TNF activity that was neutralised by monoclonal antibody to TNF alpha occurred in $13(30 \%)$ of 44 samples. Raised TNF levels were not associated with anyo particular disease type or routine laboratory markers of inflammation but were related to disease duration in osteoarthritis. The finding of biologically active TNF in symptomatic joints of arthritię patients supports the idea that it may contribute to the pathogenesis of joint damage in chronie rheumatic diseases.

Key word: arthritis.

Cytokines are inducible peptides with receptor mediated biological actions on many different cellular targets. Cytokine production has mainly been associated with leucocyte or fibroblastoid cells during responses to injury or infection. ${ }^{12}$ Tumour necrosis factors (TNFs) are cytokines that have recently been characterised at molecular level. ${ }^{34}$ TNF alpha (also called cachectin) is a $17000 \mathrm{Mr}$ peptide that forms biologically active oligomers. ${ }^{5}$ Mononuclear phagocytes are potent sources of TNF alpha, ${ }^{6}$ but $\mathrm{T}$ cells also produce a similar molecule ${ }^{7}$ as well as the related product, lymphotoxin (also called TNF beta). ${ }^{8}$ Resting cells release little or no TNF alpha, but after activation mRNA accumulates and TNF peptide appears soon after. ${ }^{9}$ The biological activities of human TNF alpha are similar to those of interleukin 1 (IL1) alpha and beta except that human TNF does not activate murine $\mathrm{T}$ cells. ${ }^{10}$

The biological role of TNF has not yet been completely defined, but its properties in vitro and in vivo suggest it could be an important mediator of host defence against tumours and pathogens. ${ }^{11}$ It is also likely that TNF may contribute to autoimmune and inflammatory pathology such as occurs in rheumatic diseases. The defined activities of TNF relevant to arthritis include resorption of cartilage and bone ${ }^{12}$ 13; endothelial adherence and activation

Accepted for publication 19 February 1988.

Correspondence to Dr Gordon W Duff, University of Edinburgh Department of Medicine, Rheumatic Diseases Unit, Northern General Hospital, Ferry Road, Edinburgh EH5 2DQ, UK. of granulocytes ${ }^{14} 15$; stimulation of fibroblas $\overrightarrow{0}$ growth ${ }^{16}$; stimulation of synovial cell prostaglaninipo and collagenase release ${ }^{17}$; and the systemic reactionis of fever, ${ }^{18}$ liver acute phase protein synthesis, ${ }^{19}$ and catabolism of protein and fat leading to muscle loss and cachexia. ${ }^{20}$ Whether resident cells in healthy skeletal tissues include populations that producep TNF is not known, but the mononuclear infiltrating cells that characterise synovial pathology in many arthritic diseases are likely sources of TNF. Cyto kine studies in arthritis have previously concen trated on interleukins 1 and 2 and interferons, ${ }^{21}$ but the connective tissue effects of TNF raise the possibility that it may mediate bone and cartilages injury in chronic joint disease. ${ }^{20}$

As there was no previous information on the occurrence of TNF in human arthritic diseases we tested unfractionated synovial exudate fluids frong 137 patients with different rheumatic diseases and report here that biologically significant levels of TNF alpha were found in approximately $30 \%$ of the samples.

\section{Materials and methods}

S YNOVIAL FLUIDS

Synovial effusion fluids (SF) were obtained fronf

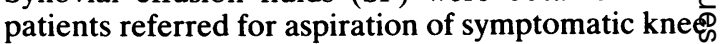
joints. Clinical diagnoses covered a wide range of rheumatic diseases as indicated in the results $\sec _{\overline{0}}^{-}$ tion. All of the patients were being treated with non $\frac{\vec{D}}{\mathrm{C}}$ steroidal anti-inflammatory drugs and some्ष 
received slow acting anti-inflammatory drugs or low dose oral corticosteroids. Fluids were collected in sterile containers in the presence of $5 \times 10^{-3} \mathrm{M}$ edetic acid, centrifuged at $1800 \mathrm{~g}$ for 30 minutes, and sample aliquots stored at $-70^{\circ} \mathrm{C}$ or tested immediately for TNF content. The fluids were collected over 16 months.

\section{RE A G E N T S}

Human recombinant (HR) TNF alpha, human recombinant lymphotoxin (TNF beta), mouse monoclonal antibody specific for human TNF alpha and rabbit antiserum against HR lymphotoxin were all kindly donated by Dr Gunther Adolf (ErnstBoehringer-Institut fur Arzneimittel-Forschung, A1121 Wien, Austria). HR IL1 alpha and IL1 beta were obtained from Biogen (Geneva). Reagents for immunoradiometric assay for human interferon gamma were from Boots-Celltech (Slough, Berkshire).

TNF A S S A

The conventional bioassay for TNF activity based on cytotoxicity for the mouse connective tissue cell line L929 was used. ${ }^{22}$ Briefly, L929 cells were cultured in Eagle's minimum essential medium (Sigma, St Louis, MO) with $5 \%$ fetal calf serum (Gibco, Paisley, UK) at $4 \times 10^{4}$ cells/well for 20 hours in flat bottomed, 96 well, microtitre plates. The medium above the non-confluent cell layer was replaced with fresh medium containing actinomycin $D(1 \mu \mathrm{g} / \mathrm{ml})$ and serial dilutions of standard HR TNF alpha or samples to be tested for TNF content. After a further 20 hour incubation the medium was removed and a $0.5 \%$ in $20 \%$ methanol solution of crystal violet was added to the wells. The number of viable (adherent) cells remaining in each well was assessed by scanning spectrophotometry (Dynatech MR 700) at $540 \mathrm{~nm}$. The concentration of TNF giving $50 \%$ maximal cell killing (one bioassay unit) was equivalent approximately to $50 \mathrm{pg} / \mathrm{ml}$ of recombinant human TNF alpha. A range of cytokines, including recombinant and purified natural IL1 alpha and beta, purified interferon alpha and recombinant interferon gamma, and crude interleukins 2 and 3 , gave no appreciable activity (less than 4 units $/ \mathrm{ml}$ ) in this assay but HR lymphotoxin was equipotent with TNF alpha.

Synergy between interferon gamma and TNF has been reported for human cell cytotoxicity ${ }^{23}$ and in other human systems. ${ }^{24}$ Therefore we measured interferon gamma levels in these synovial exudates. Of $27 \mathrm{SF}$ tested for IFN gamma in a specific radioimmunometric assay, none reached the detection limit $(1 \mathrm{U} / \mathrm{ml})$. With this assay there was no loss of detection of HR interferon gamma added to osteoarthritis or rheumatoid arthritis synovial fluids compared with culture medium.

Ninety three SF were tested at 11 serial dilutions in at least three separate assays, from which quantitative data (units of TNF activity) could be derived.

\section{SPECIFICITY TESTING}

To test that the L929 cytotoxicity of the SF was mediated by TNF alpha some positive samples were reassayed in the presence of monoclonal antibody (MAb) specific for HR TNF alpha or MAb specific for human major histocompatibility complex (MHC) class II product (control antibody). These quantitative experiments indicated that some cytotoxic samples were not neutralised by anti-TNF alpha. To determine the proportion of fluids with cytotoxic activity that were neutralised by anti-TNF alpha we tested a further 44 fresh fluids at one dilution only (1:8) after preincubation with culture medium, anti-TNF alpha, irrelevant MAb, or a rabbit antiserum against $\mathrm{HR}$ lymphotoxin.

It is known that both IL1 alpha (di Giovine, Poole, and Duff, unpublished observation) and beta $^{25}$ are detectable by radioimmunoassay in human synovial exudate fluids. IL1 is reported to act synergistically with TNF in a number of biological systems. ${ }^{26-28}$ To test whether our bioassay estimate of TNF content might be influenced by synovial fluid IL1 we performed L929 bioassays of HR TNF in the presence of HR IL1 alpha and beta. Fig. 1 shows that IL1 did not affect the L929 response to TNF alpha.

\section{Results}

TNF-LIKE ACTIVITY IN SYNOVIAL FLUIDS Of the first 93 SF tested, 35 had TNF-like activity of $4 \mathrm{U} / \mathrm{ml}$ or greater. Table 1 summarises the clinical diagnosis and level of TNF-like activity. The two positive fluids in the miscellaneous group were from patients with recurrent monarthritis. Several SF with the highest levels had been assayed fresh, suggesting that activity may be lost after freezethawing or storage at $-70^{\circ} \mathrm{C}$.

ANTIBODY NEUTRALISATION OF TNF-LIKE A C TIVITY

Eight of the 35 fluids with TNF-like activity were retested in full titrations alone or with anti-TNF alpha, or control MAb (Table 2). Six were completely neutralised by anti-TNF alpha but two were not, suggesting that other cytotoxins were present in these samples. To determine the proportion of SF that contained cytotoxic activity attributable to TNF alpha we tested a new group of $44 \mathrm{SF}$ in triplicate at 
one dilution only, either alone or with antibodies. Of these 44 fluids, $13(30 \%)$ contained TNF activity that was unaffected by control antibody but completely neutralised with anti-TNF. They included SF from patients with rheumatoid arthritis, osteoarthritis, ankylosing spondylitis, psoriatic arthritis, reactive arthritis, septic arthritis, and gout. SF that did not contain TNF activity were also found from patients in most of these disease groups. Twenty three samples $(52 \%)$ contained no TNF-like activity at all and eight $(18 \%)$ were cytotoxic for L929 cells? but either were not neutralised with anti-TNF of were affected by the irrelevant MAb. Notably, of the $21 \mathrm{SF}$ that were cytotoxic for L929, none was neutralised by antiserum to lymphotoxin. This antiserum at 1:800 dilution completely inhibited the activity of $10 \mathrm{ng} / \mathrm{ml}$ human recombinant lymphoळ toxin in the L929 assay.

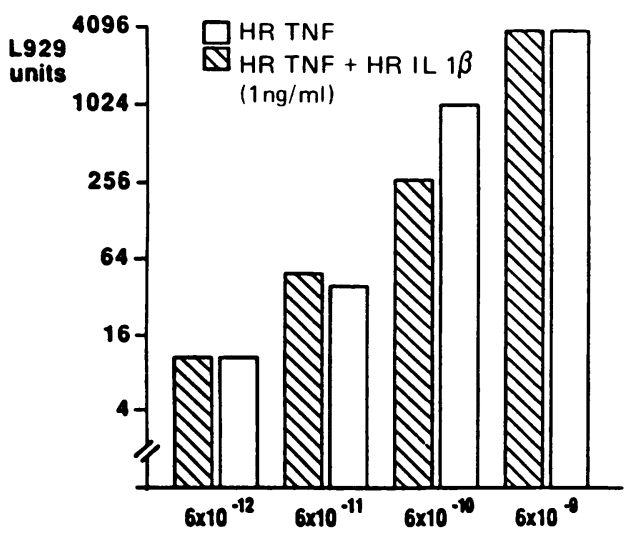

HR TNF $(\mathrm{mol} / \mathrm{l})$

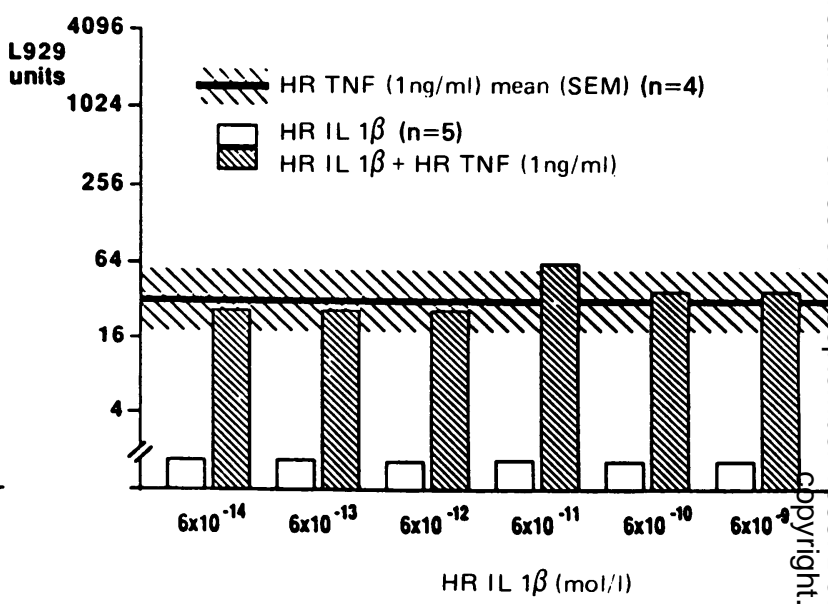

b

Fig. 1 Human recombinant tumour necrosis factor (HR TNF) alpha and HR interleukin 1 beta (IL IB) were tested for synergy in the L929 cytotoxicity assay. (a) Different concentrations of HR TNF alpha were tested in the presence or absence of HR ILI beta $(1 \mathrm{ng} / \mathrm{ml})$. (b) HR TNF alpha $(1 \mathrm{ng} / \mathrm{ml})$ was tested in the presence or absence of different concentrations of HR ILI beta. No synergy in L929 cytotoxicity was observed and HR ILI beta alone in a wide concentration range was inactive in this assay. Identical results (data not shown) were obtained in separate experiments in which TNF was tested at higher concentrations $(10 \mathrm{ng} / \mathrm{ml})$ or HR ILI alpha was used. Biological activity of both ILI preparations was confirmed by EL4.NOB.1/CTLL conversion assay.

Table 1 TNF activity in SF from patients with different rheumatic diseases

\begin{tabular}{|c|c|c|c|c|c|c|c|c|}
\hline $\begin{array}{l}\text { TNF activity* } \\
(\mathrm{U} / \mathrm{ml})\end{array}$ & $R A+$ & $R A-$ & $O A$ & $\operatorname{ReA}$ & $P s A$ & $A S$ & Misc & Total \\
\hline$<4$ & $29+$ & 11 & 6 & 2 & 3 & 1 & 6 & 58 \\
\hline $4-16$ & 9 & 7 & 3 & 4 & 2 & 1 & 1 & 27 \\
\hline $16-28$ & 2 & & 1 & 1 & & 1 & & 5 \\
\hline $28-40$ & & & 1 & & & & & 1 \\
\hline $40-52$ & 1 & & & & & & & 1 \\
\hline$>52$ & & & & & & & 1 & 1 \\
\hline Total & 41 & 18 & 11 & 7 & 5 & 3 & 8 & 93 \\
\hline$\%$ Positive $\ddagger$ & 29 & 39 & 46 & 71 & 40 & 67 & 25 & 38 \\
\hline
\end{tabular}

RA+=seropositive rheumatoid arthritis; $\mathbf{R A}==$ seronegative rheumatoid arthritis; $O A=0$ steoarthritis; $R \mathbf{A}=$ reactive arthritis; PsA=psoriatic arthritis; $\mathbf{A S}=$ ankylosing spondylitis; Misc=miscellaneous group.

*Each synovial fluid was measured at least three times at 11 dilutions in different assays.

†Number of patient SF in this category.

$\ddagger$ Percentage of patients in each category with TNF levels $>4 \mathrm{U} / \mathrm{ml}$ (detection limit). 
Table 2 Antibody neutralisation of synovial fluid TNF-like activity

\begin{tabular}{|c|c|c|c|}
\hline & $\begin{array}{l}\text { Sample } \\
\text { alone }\end{array}$ & $\begin{array}{l}\text { Sample with } \\
\text { anti-TNF+ }\end{array}$ & $\begin{array}{l}\text { Sample with } \\
\text { anti-DR }\end{array}$ \\
\hline SF 73 (OA) & $39^{*}$ & $<4$ & 34 \\
\hline SF 69 (AS) & 42 & $<4$ & 41 \\
\hline SF 78 (OA) & 14 & $<4$ & ND§ \\
\hline SF $158(\mathrm{OA})$ & 11 & $<4$ & 11 \\
\hline SF $161(\mathrm{RA}+)$ & 50 & $<4$ & 49 \\
\hline SF $91(\mathrm{RA}+)$ & 5 & $<4$ & ND \\
\hline SF $116(\mathrm{RA}+)$ & 19 & 5 & 10 \\
\hline SF $112(\operatorname{ReA})$ & 7 & 9 & ND \\
\hline HR LT $(1 \mathrm{ng} / \mathrm{ml}) \S$ & 24 & 22 & 30 \\
\hline HR TNF $(1 \mathrm{ng} / \mathrm{ml})$ & 22 & $<4$ & 21 \\
\hline
\end{tabular}

${ }^{*}$ Values are TNF bioassay units/ml.

†Monoclonal antibody against human recombinant TNF alpha (1:1600).

$\ddagger$ Monoclonal antibody against human MHC class II product as control antibody (1:800).

$\S$ HR LT=human recombinant lymphotoxin; $\mathrm{ND}=$ not done; other abbreviations as in Table 1.

\section{Discussion}

The purpose of this study was to test whether unfractionated synovial exudate fluids from arthritic patients contained biologically active TNF. Using a bioassay for TNF based on cytotoxicity for the murine L929 connective tissue cell line we tested a total of 137 synovial exudate fluids. In quantitative assays for TNF activity 35 (38\%) of 93 samples were positive at a concentration of at least $4 \mathrm{U} / \mathrm{ml}$ (the limit of detection). In six of eight positive SF tested, TNF-like activity was neutralised by monoclonal anti-TNF alpha. Of a further 44 fluids that were tested in a single dilution assay, $13(30 \%)$ contained TNF activity neutralised only by MAb for TNF alpha. None of the 21 cytotoxic samples in this series was neutralised by antiserum to lymphotoxin.

TNF alpha was found in SF from patients with a variety of rheumatic diseases, but in this preliminary study we noted no association between synovial fluid TNF level and disease category, drug treatment, or laboratory data (haemoglobin, white cells, platelets, erythrocyte sedimentation rate). The only significant difference in clinical terms was in disease duration in osteoarthritis and reactive arthritis, where those with detectable TNF levels had a mean duration of disease of $9 \cdot 3$ years $(n=10)$, while similar patients with no detectable TNF had mean disease duration of 3.3 years $(n=14, p=0.0067)$. Presumably, systemic markers of inflammation are more likely to be related to levels of TNF in the circulation rather than in the synovial space.

There have been recent reports of TNF in samples from patients with meningococcal ${ }^{29}$ or protozoal $^{30}$ infections and in cancer, ${ }^{31}$ but no previous reports of TNF in sterile inflammatory diseases seem to be available. Our results indicate that about $30 \%$ of synovial exudates from different rheumatic diseases contain biologically detectable levels of TNF alpha (equivalent to nanomolar concentrations of $\mathrm{HR}$ TNF). The presence of TNF in synovial exudate from several rheumatic diseases argues against TNF production as a specific factor in the pathogenesis of any particular disease. It seems that TNF may be associated with the process of joint effusion that is common to a number of articular disorders with apparently different aetiologies. This is in keeping with the known variety of stimuli able to induce TNF production in mononuclear cell populations. For example, monosodium urate crystals stimulate monocyte TNF release in vitro, ${ }^{32}$ which could account for TNF in gouty effusions. Presumably, in septic arthritis macrophage TNF production is directly stimulated by microbial products, and TNF release could be a direct or indirect result of lymphocyte activation in both acute and chronic rheumatic diseases. It is likely that these biodetection results underestimate the amount of TNF present as in some fluids we could detect only $50-60 \%$ of known quantities of added HR TNF alpha. It is also possible that TNF activity was lost on prolonged storage or during freeze-thawing as the highest levels we found were in fresh or recently collected samples. Finally, the assay itself is relatively insensitive and preliminary findings with more sensitive immunoassays indicate that TNF is detectable in a much larger proportion of samples.

As TNF is known to activate polymorphonuclear cells, ${ }^{14}{ }^{15}$ stimulate synovial prostaglandin production, ${ }^{17}$ and increase bone ${ }^{13} 33$ and cartilage ${ }^{12}$ destruction in vitro, its presence in synovial effusion fluids may well be significant. Recently, TNF has also been shown to induce other cytokines, including IL1 and granulocyte-monocyte colony stimulating factor. ${ }^{18}{ }^{34}$ IL1 is, like TNF, proinflammatory and catabolic ${ }^{21}$ and is found in human synovial exudates. $^{25} 3536$ It is made by synovial cells ${ }^{37} 38$ and was reported to be arthritogenic when injected into rabbit joints. ${ }^{39}$ In addition to IL1 induction by TNF, IL1 itself has been shown to increase TNF activity, ${ }^{40}$ suggesting a mechanism for the maintenance of inflammation.

This report now provides evidence that TNF alpha in a biologically active form occurs at the site of inflammation in several types of arthritis and supports the idea that mononuclear cytokines mediate joint tissue destruction. ${ }^{41}$ An understanding of the cellular origins and activators of these cytokines should help elucidate the pathogenesis of several types of rheumatic disease. 
This work was supported by a programme grant from the Arthritis and Rheumatism Council for Research (UK). We are very grateful to Miss Anne S Mitchell for the preparation of this manuscript.

\section{References}

1 Dinarello C A. Interleukin-1: amino acid sequences, multiple biological activities and comparison with tumor necrosis factor (cachectin). The year in immunology. Vol 2. Basel: Karger. 1986: 68-89.

2 Beutler B. Cerami A. Cachectin and tumour necrosis factor as two sides of the same biological coin. Nature 1986: 320: 584-8.

3 Pennica D. Nedwin G E. Hayflick J S. et al. Human tumour necrosis factor: precursor structure. expression and homology to lymphotoxin. Nature 1984: 312: 724-9.

4 Gray P W. Aggarwal B B. Denton C V. et al. Cloning and expression of cDNA for human lymphotoxin, a lymphokine with tumor necrosis activity. Nature 1984: 312: 721-4.

5 Aggarwal B B. Kohr W J. Hass P E. et al. Human tumour necrosis factor. Production. purification and characterization. $J$ Biol Chem 1985: 260: 2345-54.

6 Matthews N. Tumour necrosis factor from the rabbit. II. Production by monocytes. Br J Cancer 1978; 38: 310-5.

7 Turner M. Londei M. Feldmann M. Human T cells from autoimmune and normal individuals can produce tumor necrosis factor. Eur J Immunol (in press).

8 Koyabashi M. Plunkett J M. Masunaka I K. Yamamoto R S. Granger G A. The human LT system. XII. Purification and functional studies of LT and 'TNF-like' LT forms from a continuous human $T$ cell line. J Immunol 1986: 137: 1885-92.

9 Beutler B. Krochin N. Milsark I W. Luedke C. Cerami A Control of cachectin (tumor necrosis factor) synthesis: mechanisms of endotoxin resistance. Science 1986: 232: 977-80.

10 di Giovine F. Malawista S E. Nuki G. Duff G W. Interleukin 1 (IL-1) as a mediator of crystal arthritis. Stimulation of T cell and synovial fibroblast mitogenesis by urate crystal-induced ILI. $J$ Immunol 1987: 138: 3213-8.

11 Taverne J. Matthews N. Depledge P. Playfair J H L. Malarial parasites and tumour cells are killed by the same component of tumour necrosis serum. Clin Exp Imminol 1984; 57: 293-9.

12 Saklatvala J. Tumour necrosis factor alpha stimulates resorption and inhibits synthesis of proteoglycan in cartilage. Nature 1986: 322: 547-9

13 Bertolini D R. Nedwin G E. Bringman T S. Smith D D. Mundy G R. Stimulation of bone resorption and inhibition of bone formation in vitro by human tumor necrosis factor. Nature 1986 : 319: $516-8$

14 Gamble J R. Harlan J M. Klebanoff S J. Vadas M A. Stimulation of the adherence of neutrophils to umbilical vein endothelium by human recombinant tumor necrosis factor Proc Natl Acad Sci USA 1985; 82: 8667-71.

15 Shalaby M R. Aggarwal B B, Rinderknecht E. Svedersky L P. Finkle B S. Palladino M A. Activation of human polymorphonuclear neutrophil functions by interferon-gamma and tumor necrosis factors. $J$ Immunol 1985; 135: 2069-73.

16 Vilcek J, Palombella V J. Henriksen-DeStefano D, et al. Fibroblast growth enhancing activity of tumour necrosis factor and its relationship to other polypeptide growth factors. $J$ Exp Med 1986: 163: 632-43

17 Dayer J M. Beutler B. Cerami A. Cachectin/tumor necrosis factor stimulates collagenase and prostaglandin $\mathrm{E}_{2}$ production by human synovial cells and dermal fibroblasts. $J$ Exp Med 1985: 162: 2163-8.

18 Dinarello C A. Cannon J G. Wolff S M, et al. Tumor necrosis factor (cachectin) is an endogenous pyrogen and induces production of interleukin 1. J Exp Med 1986; 163: 1433-50.

19 Darlington G J. Wilson D R. Lachman L B. Monocyteconditioned medium, interleukin 1 and tumour necrosis factor stimulate the acute phase response in human hepatoma cells in vitro. J Cell Biol 1986; 103: 787-93.
20 Beutler B. Cerami A. Cachectin: more than a tumor necros factor. New Engl J Med 1987; 316: 379-85.

21 Nuki G. Duff G (eds). Interleukin 1. BrJ Rheumatol 1985: 24 (suppl 1): 1-234.

22 Flick D A. Gifford G E. Comparison of in vitro cell cytotox assavs for tumor necrosis factor. J Immunol Methods 1984; 6 $167-75$

23 Williamson B D. Carswell E A. Rubin B Y. Prendergast J Old L L. Human tumour necrosis factor produced by human $\mathrm{B}_{\mathrm{D}}$ cell lines: synergistic cytotoxic interaction with human intep feron. Proc Natl Acad Sci USA 1983; 80: 5397-401

24 Pujol-Borrel R. Todd J. Doshi M. et al. HLA class II induction in human islet cells by interferon gamma plus tumour necros? factor or lymphotoxin. Nature 1987; 326: 304-6.

25 di Giovine F S. Situnayake R D. Duff G W. Radioimmunoassa $\overrightarrow{0}$ of interleukin 1 beta in acute and chronic rheumatic disease? Br J Rheumatol 1987; 26 (suppl 1): 34.

26 Elias J A. Gustilo K, Baeder W, Freundlich B. Synergistic stimulation of fibroblast prostaglandin production by recona binant interleukin 1 and tumour necrosis factor. $J$ Imminios 1987: 138: 3812-6.

27 Ruggiero V. Baglioni C. Synergistic anti-proliferative activity \& interleukin 1 and tumour necrosis factor. J Immunol 1987: 138 661-3.

28 Stashenko F E. Dewhirst F E, Peros W J, Kent R L, Ago J M. Synergistic interactions between interleukin 1, tumour necros factor and lymphotoxin in bone resorption. J Immunol $198 \mathbb{1}$ 138: $1464-8$.

29 Waage A. Halstensen A. Espevik T. Association betwee tumour necrosis factor in serum and fatal outcome in patiento with meningococcal disease. Lancet 1987; i: 355-7.

30 Scuderi P. Sterling K E. Lam K S, et al. Raised serum leved tumour necrosis factor in parasitic infections. Lancet 198 if $1364-5$.

31 Balkwill F. Osborne R. Burke F. et al. Evidence for turmb necrosis factor/cachectin production in cancer. Lancet 198\%; i 1229-32.

32 di Giovine F S. Nuki G. Duff G W. Release of tumour necrosos factor activity from mononuclear cells stimulated with crystalo Br J Rheumatol 1987: 26 (suppl 1): 33.

33 Thomson B M. Mundy G R. Chambers T J. Tumor necros factor alpha and beta induce osteoblastic cells to stimulaf osteoclastic bone resorption. J Immunol 1987; 138: 775-9.

34 Munker R. Gasson J. Ogawa M. Koeffler H P. Recombina $\vec{Z}$ human TNF induces production of granulocyte-monocye colony-stimulating factor. Nature 1986; 323: 79-82.

35 Wood D D. Ihric E H. Dinarello C A. Cohen P L. Isolation ஓु an interleukin-1-like factor from human joint effusions. Arthrit: Rheum 1983: 26: 975-83.

36 Nouri A M E. Panayi G S, Goodman S M. Cytokines and tho chronic inflammation of rheumatic disease. 1. The presence of interleukin 1 in synovial fluid. Clin Exp Immunol 1984: 53. 295-302.

37 Wood D D. Ihrie E H. Hamerman D. Release of interleukinfrom human synovial tissuc in vitro. Arthritis Rheum 1985; $2 \frac{5}{6}$ 853-62.

38 Duff G W, Forre O, Waalen K, Dickens E, Nuki of Rheumatoid arthritis synovial dendritic cells produce interleukin 1. Br J Rheumatol 1985; 24 (suppl 1): $94-7$.

39 Pettipher E R, Higgs G A, Henderson B. Interleukin 1 induce leukocyte infiltration and cartilage proteoglycan degradation in the synovial joint. Proc Natl Acad Sci USA 1986; 83: 8749-5\$.

40 Philip R, Epstein L B. Tumor necrosis factor as immunomode lator and mediator of monocyte cytotoxicity induced by itsel gamma interferon and interleukin 1. Nature 1986; 323: 86-9.

41 Dayer J M. Breard J. Chess L, Krane S M. Participation ot monocyte/macrophages and lymphocytes in the production of 0 factor that stimulates collagenase and prostaglandin release to rheumatoid synovial cells. J Clin Invest 1979; 64: 1386-92. 